\title{
INVENTÁRIO E ANÁLISE DA ARBORIZAÇÃO NAS CALÇADAS DA REGIÃO CENTRAL DE GURUPI-TO
}

\author{
INVENTORY AND ANALYSIS OF AFFORESTATION IN SIDEWALKS IN THE \\ CENTRAL REGION OF GURUPI-TO
}

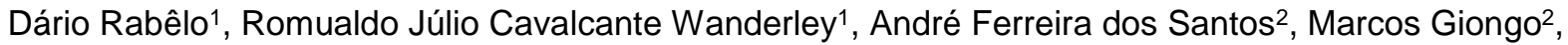 \\ Patrícia Aparecida de Souza ${ }^{3}$
}

\section{RESUMO}

O trabalho teve como objetivo analisar a arborização nas calçadas no centro da cidade de Gurupi-TO. Foi feito um inventário, no qual se usou o procedimento de amostragem sistemática para determinação das amostras. Localizou-se dessa forma, 33 unidades amostrais, correspondendo a uma intensidade amostral de $11,22 \%$ da área de estudo, composta de aproximadamente 294 quadras. Foram inventariados 370 indivíduos pertencentes a 33 espécies, sendo que sete delas são responsáveis por mais de $82 \%$ da arborização nas calçadas. Dentre estas, Licania tomentosa (Benth.) Fritsch (oiti) representou quase $58 \%$ dos exemplares. Constatou-se nos indivíduos: mais de $71 \%$ com altura menor ou igual a seis metros; mais de $72 \%$ com primeira bifurcação abaixo de $1,80 \mathrm{~m}$ de altura; cerca de $68 \%$ com diâmetro igual ou maior que $21 \mathrm{~cm}$; cerca de $33 \%$ danificando as calçadas; quase $53 \%$ em calçadas sem redes aéreas de distribuição; e mais de $91 \%$ em situações boa e satisfatória, e apenas $0,27 \%$ foram encontrados mortos. É de suma importância o planejamento adequado da arborização na cidade, pois o mesmo contribui para minimizar os conflitos com o sistema estrutural do local, bem como para redução de transtorno à população.

Palavras-chave: Levantamento quali-quantitativo; Quadra; Vias públicas; Planejamento urbano.

\section{ABSTRACT}

The study aimed to analyze the afforestation on sidewalks in the city center of Gurupi-TO. An inventory was carried out, in which the systematic sampling procedure was used to determinate the samples. Thus, 33 sample units were located, corresponding to a sample intensity of $11.22 \%$ of the study area, composed of approximately 294 blocks. A total of 370 individuals belonging to 33 species were inventoried, and seven of them are responsible for more than $82 \%$ of the afforestation on the sidewalks. Among these, Licania tomentosa (Benth.) Fritsch (oiti) represented almost $58 \%$ of the specimens. It was observed in the individuals: more than $71 \%$ with height less than or equal to six meters; more than $72 \%$ with first bifurcation below $1.80 \mathrm{~m}$ in height; about $68 \%$ with a diameter equal to or greater than $21 \mathrm{~cm}$; about $33 \%$ damaging the sidewalks; almost $53 \%$ on sidewalks without distribution air networks; and more than $91 \%$ in good and satisfactory situations, and only $0.27 \%$ were found dead. The appropriate planning of the afforestation in the city is of great importance, since it contributes to the minimization of conflicts with the local structural system, as well as reducing disturbance to the population.

Keywords: Qualitative and quantitative surveys; Block; Public roads; Urban planning.

Recebido em 14.09.2017 e aceito em 05.01.2018

1 Engenheiro Florestal. Graduado. Universidade Federal do Tocantins. Gurupi-TO. Email: dario.rabelo@yahoo.com.br, julio_cavalcanti@hotmail.com

2 Engenheiro Florestal. Dr. Prof. do Programa de Pós-Graduação em Ciências Florestais e Ambientais. Universidade Federal do Tocantins. Gurupi-TO. Email: andrefs@uft.edu.br, giongo@uft.edu.br

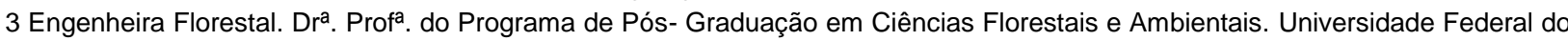
Tocantins. Gurupi-TO. Email: patriciaapsouza@uft.edu.com.br 


\section{INTRODUÇÃO}

A arborização urbana em nosso país é considerada um tema recente, de evolução lenta e com a qual as administrações públicas e a comunidade devem envolver-se, cumprindo papéis distintos (ROMANI et al., 2012). Com isso, os estudos se fazem cada vez mais necessário, principalmente, à medida que eles comprovam a contribuição da arborização na melhoria da qualidade ambiental, gerando efeitos psicológicos e físicos positivos, como a melhoria microclimática e diminuição da poluição (ALMEIDA; RONDON NETO, 2010; SILVA et al., 2007).

Entretanto, dada a sua grande importância, a arborização deve ser bem planejada de forma a poder propiciar ainda mais benefícios diretos e indiretos à população. Infelizmente, muitas cidades brasileiras não possuem um planejamento correto da arborização urbana. Em grande parte das cidades do Estado do Tocantins é facilmente possível constatar essa realidade.

Para o planejamento da arborização urbana, a primeira coisa a fazer é o inventário, que é uma ferramenta fundamental. Com o inventário pode-se obter informações a respeito da arborização presente no ambiente urbano, de forma que seja possível conhecer as espécies presentes nestes locais e seu estado de saúde, bem como estudar como se distribuem no território (SILVA; LEITE; TONELLO, 2014). Logo, de acordo com Oliveira et al. (2017), com o diagnóstico da área obtido pelo inventário, é possível analisar a situação da arborização e, assim, identificar os problemas que precisam ser solucionados.

Os inventários para arborização urbana, quanto à obtenção dos dados, podem ser classificados em dois tipos principais, segundo a sua abrangência: o inventário total ou censo e o inventário por amostragem (SILVA; GONÇALVES; LEITE, 2005). No primeiro, os indivíduos da população são observados e medidos, obtendo-se os parâmetros de toda a população. Em relação ao segundo, adota-se o procedimento de amostragem, sendo observada apenas parte da população e, consequentemente, obtém-se uma estimativa dos seus parâmetros, todavia, com uma margem de erro de amostragem. Tal erro admissível a 10\%; e raramente encontramse trabalhos onde o erro de amostragem seja inferior a $5 \%$ ou superior a $20 \%$ (SILVA; GONÇALVES; PAIVA, 2007). Atualmente, segundo os mesmos autores, não se questionam mais a validade dos processos de amostragem, visto que a sua eficiência já foi provada ao longo do tempo.

Diante do cenário exposto, o presente trabalho teve como objetivo analisar a situação da arborização urbana nas calçadas no centro do município de Gurupi-TO, por meio do procedimento de amostragem sistemática, para assim, obter informações que possam contribuir para a definição de diretrizes de planejamento da arborização no local. 


\section{METODOLOGIA}

\section{Área de estudo}

Este trabalho foi realizado no município de Gurupi, situado na região sul do Estado do Tocantins (Figura 1A), dentro do bioma cerrado. Localiza-se a latitude $11^{\circ} 43^{\prime} 45^{\prime \prime}$ sul e a longitude 4904'07" oeste e altitude de 287 metros, com um clima predominantemente estacional com duas estações bem definidas, sendo seis meses de seca e seis meses de chuva, com uma pluviosidade média anual de $1500 \mathrm{~mm}$ e temperatura média anual entre 25 a $29^{\circ} \mathrm{C}$ (SEPLAN, 2012).

Sua população estimada em 2017 pelo Instituto Brasileiro de Geografia e Estatística (IBGE) foi de 85.523 habitantes, com uma área de aproximadamente 1.836,091 km² (Figura 1B).

A região central da cidade tem aproximadamente 306 quadras, sendo a maioria com cerca de um hectare cada. No entanto, as amostras inventariadas estavam dentro de uma população composta de aproximadamente 294 quadras (Figura 1C).

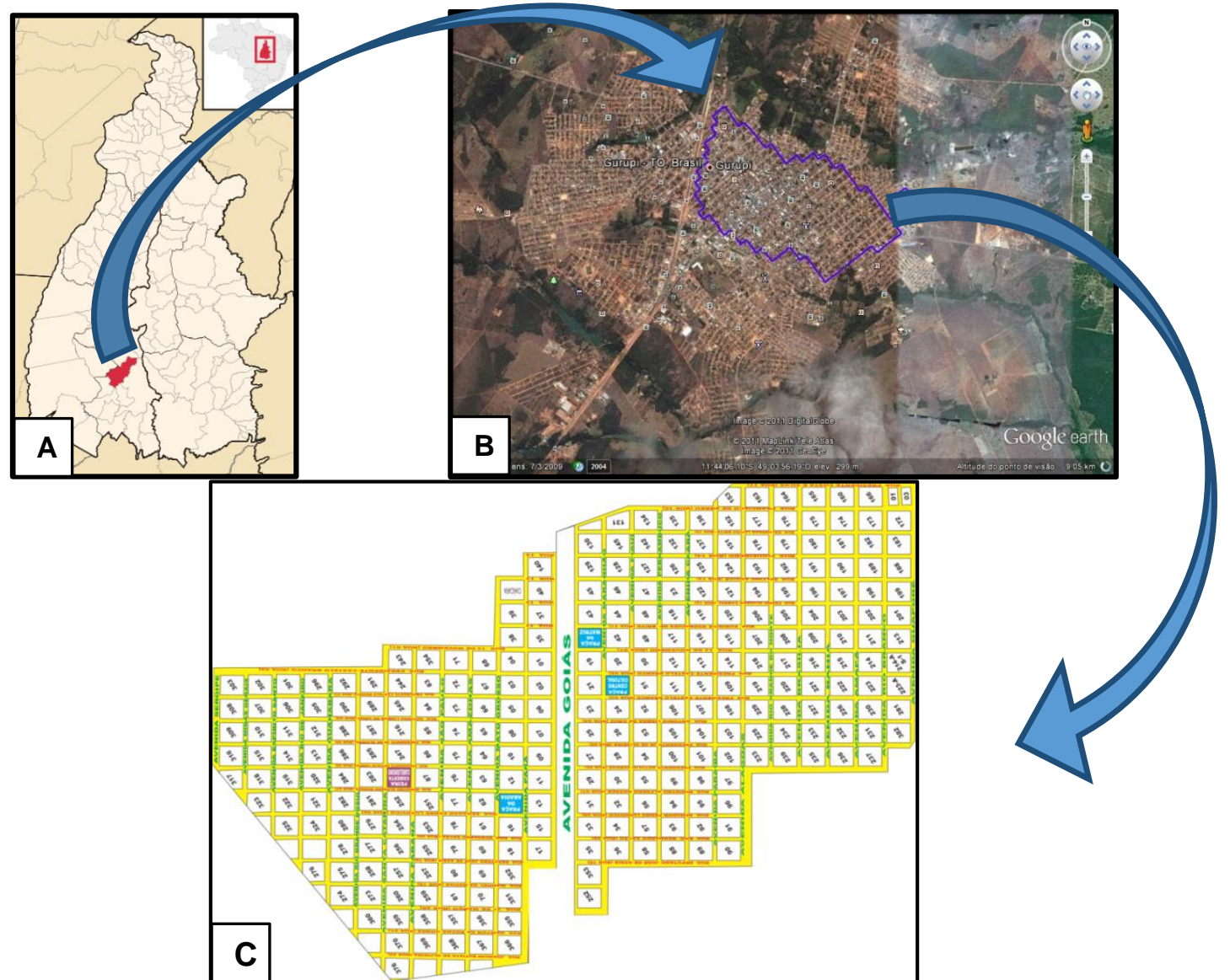

Figura 1. Localização da área de estudo: município de Gurupi na região sul do estado (A); perímetro da área de estudo dentro do município (B); e área de estudo (C)

Figure 1. Location of the study area: Gurupi city in the southern region of the state $(A)$; boundary of the study area within the city (B); And area of study (C) 


\section{Coleta dos dados}

O sistema de referência utilizado para localização das unidades amostrais (quadras) foi o mapa oficial do centro da cidade, contendo os números das quadras, nome das ruas, das avenidas e das praças (Figura 2).

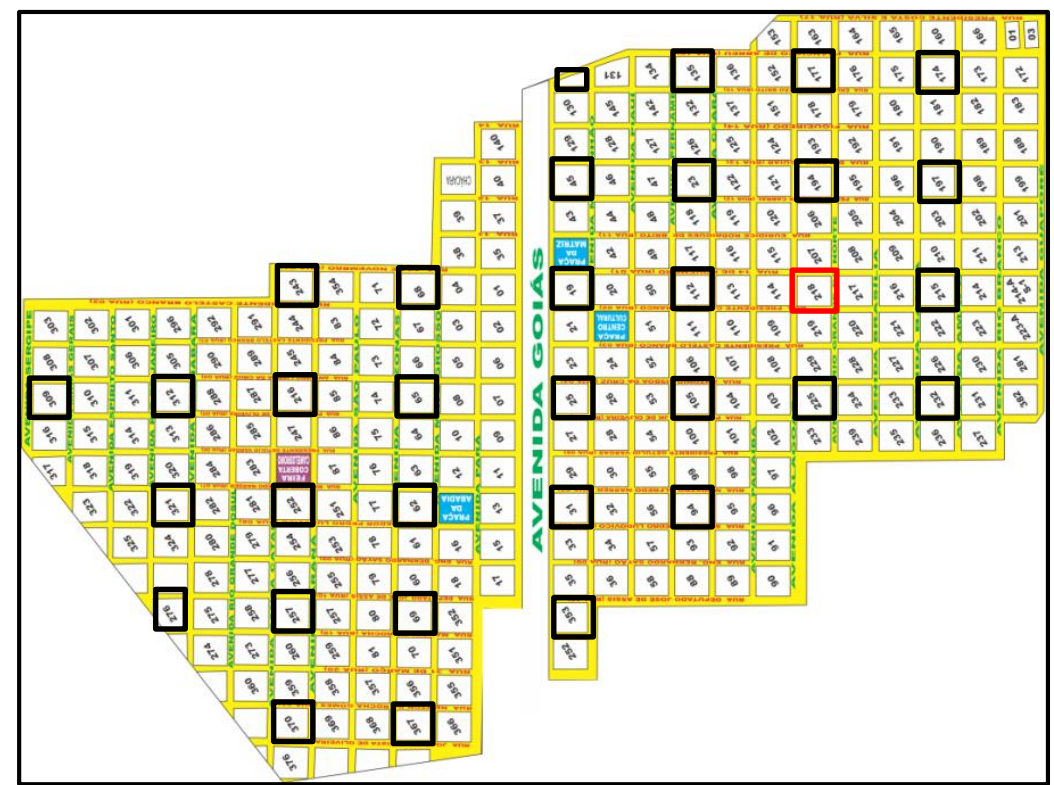

Figura 2. Quadras ou unidades amostrais selecionadas na área de estudo pelo procedimento de amostragem sistemática

Figure 2. Squares or sample units selected in the study area by the systematic sampling procedure

O levantamento foi realizado nos meses de janeiro e fevereiro do ano de 2013 , sendo de caráter quali-quantitativo. Empregou-se o método de área fixa com parcelas em forma de um quadrilátero de aproximadamente $10.000 \mathrm{~m}^{2}$ cada $(100 \mathrm{~m} \times 100 \mathrm{~m})$. Para selecionar as unidades amostrais utilizou-se o procedimento de amostragem sistemática (AS).

No inventário, após selecionar a primeira quadra aleatoriamente (quadra com borda vermelha na figura 2), deu-se início ao procedimento de amostragem sistemática, sendo da seguinte forma: nas quatro direções da amostra foi feito um caminhamento, tanto nas ruas (sentido horizontal) quanto nas avenidas (sentido vertical na área de estudo). Em cada direção, havia a intercalação de duas quadras e selecionava-se a próxima (terceira) em seguida, isto é, a distância de uma amostra para outra era um pouco mais que 200 metros. Desse modo, foram obtidas mais 32 unidades amostrais, totalizando 33, ou seja, uma intensidade amostral de $11,22 \%$ da população.

Em cada unidade amostral, nos quatro lados foram analisados todos os indivíduos (árvores, arbustos e palmeiras) presentes nas calçadas, desde que estes apresentassem diâmetro à altura do peito (DAP) maior ou igual a $7,0 \mathrm{~cm}$.

$\mathrm{Na}$ análise estatística, com objetivo de encontrar o erro de amostragem dos dados levantados, utilizou-se o formulário de Soares, Neto e Souza (2009), para analisar a eficiência 
do procedimento de amostragem, com uma intensidade de amostragem ideal (n), para assim, obter-se um erro amostral de $20 \%$ com $90 \%$ de probabilidade da média verdadeira e o número de árvores na população de estarem dentro dos intervalos de confiança.

Para anotações dos dados, usou-se o formulário citado por Silva, Gonçalves e Paiva (2007), que após receber algumas adaptações, forneceu as seguintes variáveis para serem levantadas: número da quadra e o lado em que a planta se encontrava; espécie (identificada mediante consultas bibliográficas) conforme Lorenzi (2008); diâmetro à altura do peito (DAP), mensurada com fita métrica; altura total e da primeira bifurcação, medida com régua graduada.

O diâmetro à altura do peito (DAP) foi separado em duas classes: menor ou igual a 20 $\mathrm{cm}$ e maior ou igual a $21 \mathrm{~cm}$. O intuito dessa escolha foi analisar a relação dessa variável com as outras variáveis, como exemplos: a altura total, números de vegetação adultos no local e se há constantes atividades de podas.

Referente à altura total dos exemplares inventariados foi dividida em duas classes, sendo a primeira menor ou igual a 6 metros e a segunda maior que 6 metros. O motivo de tal critério é por ter conhecimento que, árvores acima de 6 metros irão necessitar constantemente de técnicas de manejo para adequar-se ao espaço físico disponível (MARTINS et al., 2011).

Em relação à altura da primeira bifurcação dos indivíduos levantados foi dividido em duas classes, sendo: menor ou igual a 1,80 metros de altura e maior que essa altura supracitada. A presença de tal característica, acima da altura mencionada, é fundamental em muda para arborização urbana, pois evita alguns problemas (EMER et al., 2013).

As variáveis obtidas visualmente, conforme Silva, Gonçalves e Paiva (2007) foram estas: posição da copa com relação à fiação das redes aéreas de distribuição, na qual teve quatro situações: sem fiação aérea, fiação acima da copa, fiação no meio da copa e fiação abaixo da copa; fitossanidade, tendo as seguintes classes: árvore boa (o indivíduo apresentase vigoroso, sem sinais de pragas, doenças ou danos mecânicos e apresenta a forma característica da espécie, não requerendo trabalhos de correção), árvore satisfatória (apresenta condição e vigor médios para determinado local, podendo apresentar pequenos danos físicos, pequenos problemas de pragas e doenças, ou ainda necessidade de poda corretiva), árvore ruim (apresenta estágio geral de declínio e pode apresentar severos danos de pragas, doenças ou físicos e, embora não apresente morte iminente, pode requerer muito trabalho para sua recuperação), árvore morta (aparenta morte iminente) e o sistema radicular, tendo as seguintes condições de raiz: invisível (apresenta o sistema radicular subterrâneo), apenas visível (apresenta raízes expostas em passeios não pavimentados ou na área livre), quebrando a calçada (apresenta raízes expostas, principalmente na área livre e quebrando a calçada), destruindo a calçada (apresenta uma grande porção de raízes expostas destruindo a calçada, sendo visual tanto as raízes quanto parte da superfície do solo) e, invisível e 
quebrando a calçada (apresenta o sistema radicular totalmente subterrâneo, porém, quebrando a calçada).

Utilizou-se um editor de planilhas (Microsoft Office Excel 2010) tanto para análise estatística quanto para transformações dos dados em forma de gráficos.

\section{RESULTADOS E DISCUSSÃO}

\section{Espécies}

Nas calçadas, localizadas na região central da cidade de Gurupi-TO, foram inventariadas um total de 370 plantas (incluindo árvores, arbustos e palmeiras) pertencentes a 33 espécies diferentes, e apenas duas destas não foram identificadas (Tabela 1).

Tabela 1. Distribuição quantitativa das espécies encontradas nas amostras dentro da área de estudo, com os respectivos nomes científicos e comuns, frequência absoluta (FA) e relativa (FR)

Table 1. Quantitative distribution of the species found in the samples within the study area, with their respective scientific and common names, absolute frequency (AF) and relative frequency (RF)

\begin{tabular}{lccc}
\hline NOME CIENTíFICO & NOME COMUM & FA & FR (\%) \\
\hline Licania tomentosa (Benth.) Fritsch & Oiti & 213 & 57,57 \\
Pachira aquatica Aubl. & Munguba & 22 & 5,95 \\
Syzygium malaccense (L.) Merr. \& LMPerry & Jambo-roxo & 18 & 4,86 \\
Caesalpinia pluviosa DC. & Sibipiruna & 17 & 4,59 \\
Ficus benjamina L. & Ficus & 14 & 3,78 \\
Azadirachta indica A. Juss & Nim & 11 & 2,97 \\
Roystonea oleracea (Jacq.) O. F. Cook & Palmeira imperial & 10 & 2,70 \\
Murraya paniculata (L.) Jack & Jasmim-laranja & 8 & 2,16 \\
Terminalia catappa L. & Amendoeira & 6 & 1,62 \\
Não identificada 1 & & 5 & 1,35 \\
Não identificada 2 & & 4 & 1,08 \\
Averrhoa carambola L. & Carambola & 4 & 1,08 \\
Mangifera indica L. & Mangueira & 4 & 1,08 \\
Duranta erecta L. & Pingo-de-ouro & 3 & 0,81 \\
Cycas revoluta Thunb. & Palmeira cica & 3 & 0,81 \\
Phoenix roebelenii O'Brien & Palmeira fênix & 3 & 0,81 \\
Handroanthus impetiginosus (Mart. ex DC.) Mattos & Ipê-roxo & 3 & 0,81 \\
Malpighia glabra L. & Acerola & 2 & 0,54 \\
Anacardium occidentale L. & Cajueiro & 2 & 0,54 \\
Buchenavia capitata (Vahl) Eichler & Mirindiba & 2 & 0,54 \\
Syzygium jambos L.(Alston) & Jambo comum & 2 & 0,54 \\
Handroanthus albus (Cham.) Mattos & Ipê-amarelo & 2 & 0,54 \\
Caesalpinia pulcherrima (L.) Sw. & Flamboyant-de-jardim & 2 & 0,54 \\
Araucaria columnaris (J.R. Forst.) Hook. & Pinheiro-de-natal & 1 & 0,27 \\
Delonix regia (Boj. ex Hook.) Raf. & Flamboyant & 1 & 0,27 \\
\hline Tamarindus indica L. & Tamarino & 1 & 0,27 \\
Syzygium cumini L. & Jamelão & 1 & 0,27 \\
Psidium guajava L. & Goiaba branca & 1 & 0,27 \\
Psidium sp & Goiaba vermelha & 1 & 0,27 \\
Roystonea sp. & Palmeira sp. & 1 & 0,27 \\
Wallichia disticha T. & Palmeira rabo-de-peixe & 1 & 0,27 \\
Cocos nucifera L. & Coqueiro & 1 & 0,27 \\
Pinus sp. & Pinheiro & 1 & 0,27 \\
Total: & $\mathbf{3 3}$ & $\mathbf{3 7 0}$ & $\mathbf{1 0 0}$ \\
\hline & & & \\
\hline
\end{tabular}


Observou-se por intermédio da análise estatística (com uma margem de erro de amostragem chegando a 17,19\%) que cada quadra dispõe de uma média aritmética de 11,21 plantas e, com uma estimativa de 3.296 indivíduos presentes nas calçadas com DAP $\geq 7,0 \mathrm{~cm}$ no centro de Gurupi. Dados estes que se encontram dentro dos intervalos de confiança das estimativas dos parâmetros obtidos pelo procedimento de amostragem sistemática no estudo de Rabêlo et al. (2014).

No entanto, constatou-se no estudo de Oliveira et al. (2017), que englobou cerca de 37\% (108 quadras) desta mesma área de estudo, uma média de 18 indivíduos/quadra, ou seja, 5 indivíduos a mais fora do intervalo de confiança da média superior (13 plantas/quadra).

A hipótese para isso é embasada em duas suposições: a primeira é que nos seus trabalhos foram catalogados todos os indivíduos (arbóreos e arbustivos) presentes nas calçadas, independentemente do tamanho do diâmetro; e a segunda, é que o inventário dos autores citados foi executado um ano depois, havendo assim, por conseguinte, mais plantios ou desenvolvimento das mudas nas calçadas.

Verificou-se das 370 plantas inventariadas, sete espécies responsáveis por $82,42 \%$ dos indivíduos levantados, sendo elas: Licania tomentosa (Benth.) Fritsch (oiti), Pachira aquatica Aubl. (munguba), Syzygium malaccense (L.) Merr. \& LMPerry (jambo-roxo), Caesalpinia pluviosa DC. (sibipiruna), Fícus benjamina L. (fícus), Azadirachta indica A. Juss (nim) e Roystonea oleracea (Jacq.) O. F. Cook (palmeira-imperial).

Segundo Miranda et al. (2015), para um bom planejamento da arborização urbana, recomendam-se que cada espécie não ultrapasse 10 a $15 \%$ da composição total da arborização. Pois, a diversidade de espécies em uma arborização urbana pode ser empregada como um atributo para mensurar a sustentabilidade da mesma, podendo ser considerada tanto para a manutenção da diversidade de espécies quanto da diversidade genética que determinam a estabilidade, a resistência e a resiliência diante de situações desfavoráveis (RAUPP; CUMMING; RAUPP, 2006; TEIXEIRA; SILVA; TATSCH, 2011). Além disso, a não diversidade de espécies na arborização urbana propicia perdas de biodiversidade na área, ou seja, as espécies de fauna que poderiam visitar áreas urbanas, não são atraídas para tal em função de abrigos e pouca fonte de alimentação (BRUN; LINK; JOSÉ BRUN, 2007).

Analisando a tabela, apenas a espécie Licania tomentosa foi além das recomendações desses autores. A explicação para a abundância dessa espécie é devido ao viveiro municipal produzir basicamente mudas dessa espécie para fornecê-las à população. Além disso, a espécie possui estas características positivas em uma arborização urbana: perenifólia, copa globosa (fornece uma excelente sombra) e raízes profundas (LORENZI, 2008). Porém, de acordo com o mesmo autor, a desvantagem é por ser considerada de grande porte e, em razão disso, pode trazer alguns problemas no meio urbano. 
Observa-se na Tabela 1 que há baixo número de indivíduos de algumas espécies. Tal situação é comum em diversas cidades brasileiras, como a verificada por Almeida e Rondon Neto (2010) ao analisar a arborização de duas cidades da região norte do Estado do Mato Grosso. Em concordância com os autores mencionados, o baixo número pode ser atribuído à ausência de elaboração de legislação específica para atender ao planejamento urbano.

\section{Altura total e conflito com as redes aéreas de distribuição}

Ao analisar os dados em classes de alturas, constatou-se dos 370 exemplares registrados quase $72 \%$ apresentaram altura igual ou inferior a seis metros (Figura 3). Resultado esse comum na arborização urbana, principalmente sob rede aérea de energia elétrica (ALMEIDA; RONDON NETO, 2010).

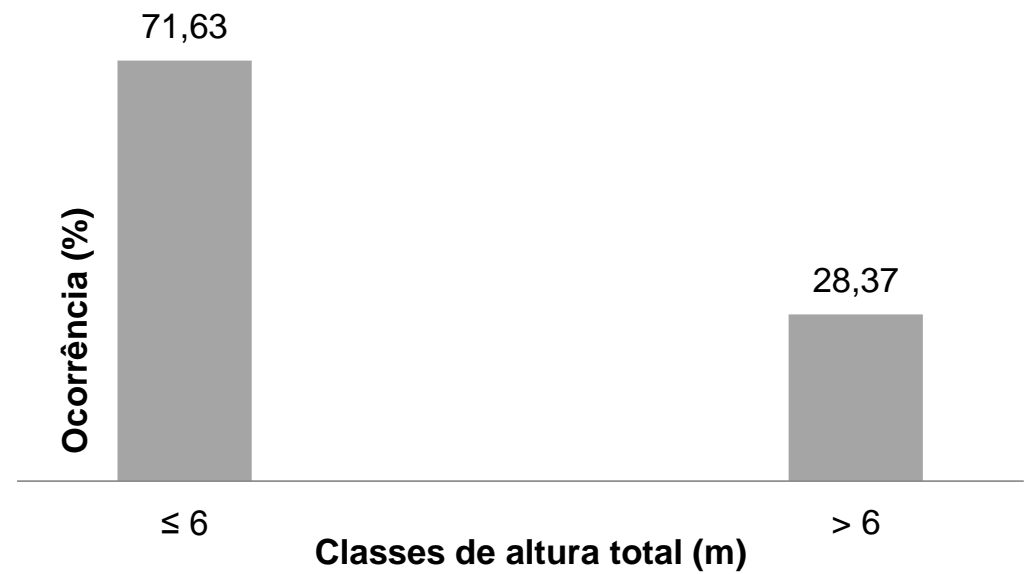

Figura 3. Distribuição da ocorrência das classes de altura total $(\mathrm{m})$

Figure 3. Distribution of the occurrence of total height classes $(\mathrm{m})$

No entanto, sabe-se que a maioria dos indivíduos inventariados (principalmente os de maiores frequências), são considerados de médio a grande porte (LORENZI, 2008). Com isso, evidencia-se que os mesmos são jovens ou a redução de seus portes é em razão de práticas de podas, visando que as mesmas não toquem na rede telefônica e depois na rede de energia elétrica. Pois, conforme Silva, Gonçalves e Paiva (2007), a rede telefônica encontra-se a 5,40 metros e a de energia elétrica de baixa e alta tensão localizam-se a 7,20 e 8,20 metros de altura, respectivamente.

Com relação a análise dos indivíduos acima de 6 metros de altura, verificou-se que cerca de $20 \%$ apresentavam conflitos com a fiação. Portanto, em conformidade com Martins et al. (2011), as classes de alturas que passam as redes de energia elétrica são mais preocupantes, pois árvores acima de 6 metros de altura irão necessitar constantemente de técnicas de manejo para adequar-se ao espaço físico disponível. 
Em relação às fiações das redes aéreas, foram encontrados $52,70 \%$ dos exemplares em calçadas em que não há nenhum tipo de rede aérea, tanto de telefônica quanto de energia elétrica (Figura 4). Valor próximo a este foi encontrado por Minhoto, Monteiro e Fisch (2009) em Taubaté-SP $(56,87 \%)$, no centro comercial histórico e um bairro residencial moderno. Percebe-se com esses dados que as redes aéreas, principalmente de energia elétrica, inibem a população ou o órgão competente (que cuida da arborização) de plantar espécies de árvores de médio ou de grande porte nessas áreas, devido ao risco que podem trazer ao meio.

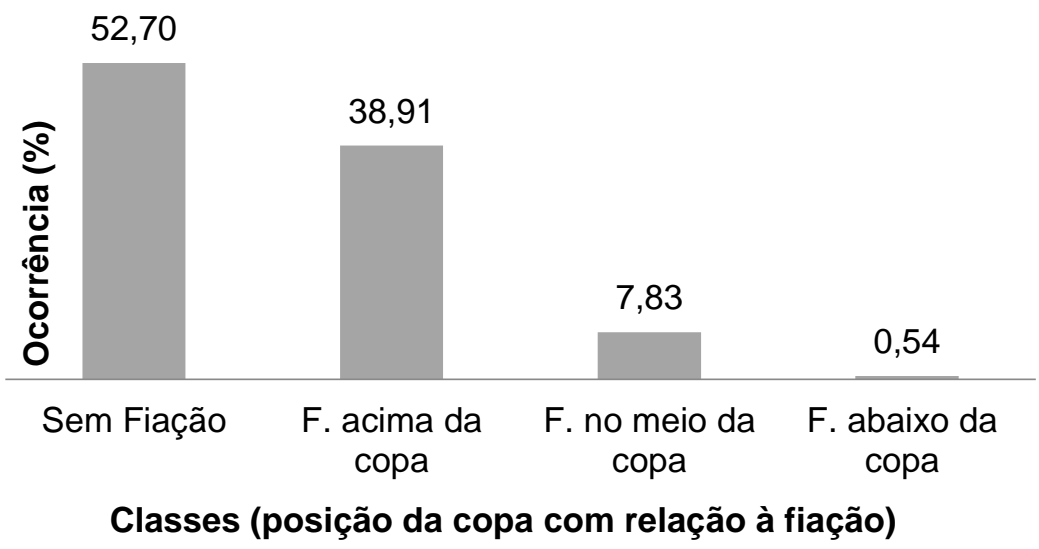

Figura 4. Distribuição das classes da posição da copa das plantas nas calçadas em relação às fiações $(F)$ da rede aérea

Figure 4. Distribution of classes of plant canopy position on sidewalks in relation to the wiring $(F)$ of the overhead

Dos restantes, 46,74\% dos indivíduos, apresentavam algum tipo de poda citada pela Secretaria Municipal do Meio Ambiente da Prefeitura de Aracruz-ES (SEMAM), para assim, livrar as fiações aéreas. Sendo assim, 38,91\% desse valor foram constatados indivíduos com a fiação acima da copa, em razão principal da presença de poda de contenção de copa, que é aquela poda, conforme Semam (2013) consiste em reduzir a altura da copa, pois, dessa maneira, irá mantê-la abaixo da fiação aérea; com fiação no meio da copa (7,83\%), alguns apresentavam poda em "V" ou em "furo" que, conforme Silva et al. (2007), essas podas são recomendadas quando a árvore atinge a sua fase mais adulta, tendo assim, contato com alguns componentes que fazem parte da infraestrutura da cidade, sobretudo a rede elétrica, visando assim acidentes; e 0,54\% apresentavam indivíduos com sua copa acima da rede aérea (Figura 5). 

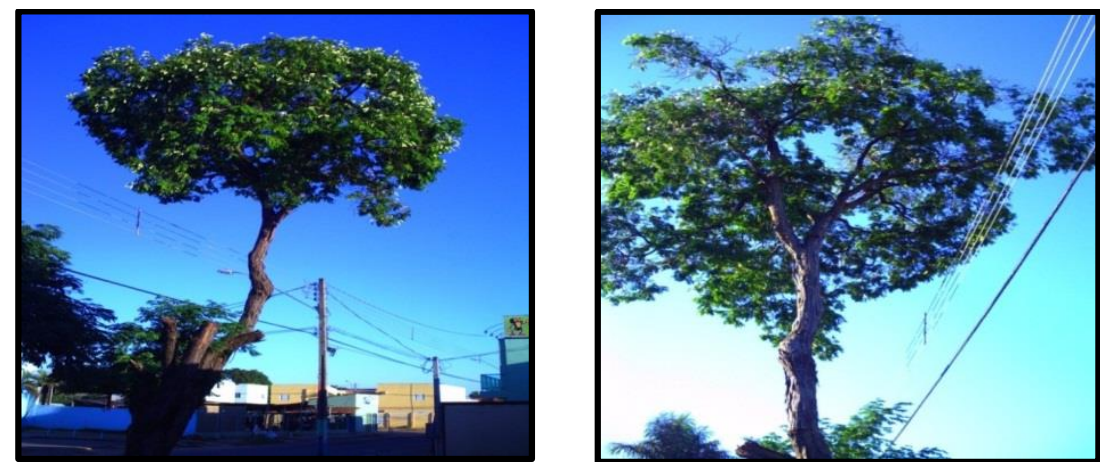

Figura 5. Árvores com a copa acima das redes aéreas de distribuição

Figure 5. Trees with the canopy above the overhead distribution networks

Em relação as podas (contenção de copa, em $\mathrm{V}$ ou em furo) citadas por Semam (2013) acabam por decorrer inúmeros problemas, como a redução dos benefícios proporcionados pelas espécies de grande porte, quanto ao fornecimento de sombra e todo um decorrente fator ecológico de relevância nas atuais áreas urbanas (TEIXEIRA; SILVA; TATSCH, 2011). Por esses motivos, é essencial que sejam realizadas por profissionais capacitados e com conhecimento de questões ligadas à anatomia, à morfologia e à fisiologia das árvores, assim poderá reduzi-los.

Desta forma, é necessário o estudo das espécies e de seus respectivos portes, para que o plantio seja realizado em locais ao qual a mesma venha interferir minimamente nos equipamentos urbanos e necessite de mínimo acompanhamento do órgão competente (MEIRA et al., 2015). Além disso, o uso de espécies de pequeno porte sob a rede pode minimizar ou tornar inexistente a poda (MINHOTO; MONTEIRO; FISCH, 2009).

\section{Diâmetro e altura da primeira bifurcação}

Referente ao diâmetro a altura do peito (DAP), quase $68 \%$ exibiam diâmetro igual ou maior que $21 \mathrm{~cm}$ (Figura 6), podendo caracterizar uma arborização com mais indivíduos adultos, como foi certificado no estudo realizado por Oliveira et al. (2017) na região central de Gurupi.

Os mesmos autores constataram-se nesta mesma área de estudo, que um pouco mais de $76 \%$ dos indivíduos inventariados estavam em área livre (canteiro) inferior a $1 \mathrm{~m}^{2}$. Resultados estes negativos para arborização urbana no local, pois, sabe-se que uma árvore chega a viver inúmeras décadas, com isso, à medida que o tempo passa seu diâmetro ou circunferência aumenta cada vez mais e, com o tempo, poderá haver a redução de $100 \%$ dessa área, resultando pressão e danos nas calçadas. 


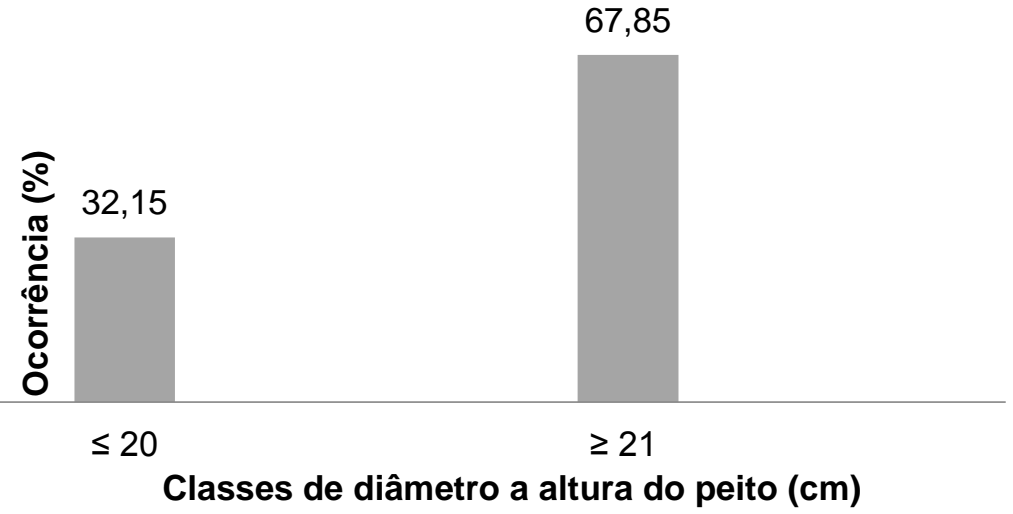

Figura 6. Distribuição do diâmetro a altura do peito (DAP) dos indivíduos $(\mathrm{cm})$

Figure 6. Distribution of the diameter at breast height $(\mathrm{DBH})$ of the individuals $(\mathrm{cm})$

Logicamente, os indivíduos com maiores alturas correspondem aos de maiores diâmetros, visto que são duas variáveis lineares diretamente proporcionais (QUISSINDO; OCONOR; LUNA, 2016). Pode-se dizer que as plantas no decorrer da vida sofreram diversas intervenções de podas para redução do seu porte, como foram mostrados na figura 3, onde se observa que $71,61 \%$ dos indivíduos apresentaram sua altura total abaixo de seis metros.

Quanto à altura da primeira bifurcação, foram encontradas muitas plantas inadequadas nas calçadas devido a essa característica (Figura 7). Pois, uma das características principais de uma muda para arborização é o início da sua primeira bifurcação. Sendo assim, é recomendável por Silva, Gonçalves e Paiva (2007) que a mesma quando for usada para plantio definitivo deve apresentar, preferencialmente, fuste com altura mínima de $1,80 \mathrm{~m}$ e, quando possuírem ramificações laterais abaixo dessa altura, submeter à poda de formação. Dessa forma, principalmente no caso da arborização de ruas, confere-se a melhor acessibilidade e deslocamento dos pedestres pela calçada, evitando que estes disputem espaço com os veículos, causem, ou sejam vítimas de acidentes (EMER et al., 2013).

Entretanto, do total de indivíduos inventariados, um pouco mais de $72 \%$ mostravam-se a sua primeira bifurcação abaixo de 1,80 metros de altura (Figura 7), ou seja, altura considerada não ideal para o local, por trazer algumas dificuldades já mencionadas. Tal situação foi encontrada com uma porcentagem ainda maior por Martins et al. (2011) quando estavam analisando a compatibilidade da arborização viária com o ambiente construído na cidade de Luiziana-PR, onde constataram que $88 \%$ das árvores possuem altura da primeira bifurcação inferior a 1,80 metros e, também por Silva, Leite e Tonello (2014), no município de Araçoiaba da Serra-SP, em que $68,22 \%$ dos indivíduos amostrados estão com o início da primeira bifurcação abaixo da altura recomendável.

Isso pode ser indicativo da baixa qualidade das mudas utilizadas na arborização, sendo atribuída, hipoteticamente, ao fato de os plantios serem realizados pelos próprios 
moradores, sem haver assim, a preocupação com aspectos técnicos (ALMEIDA; RONDON NETO, 2010).

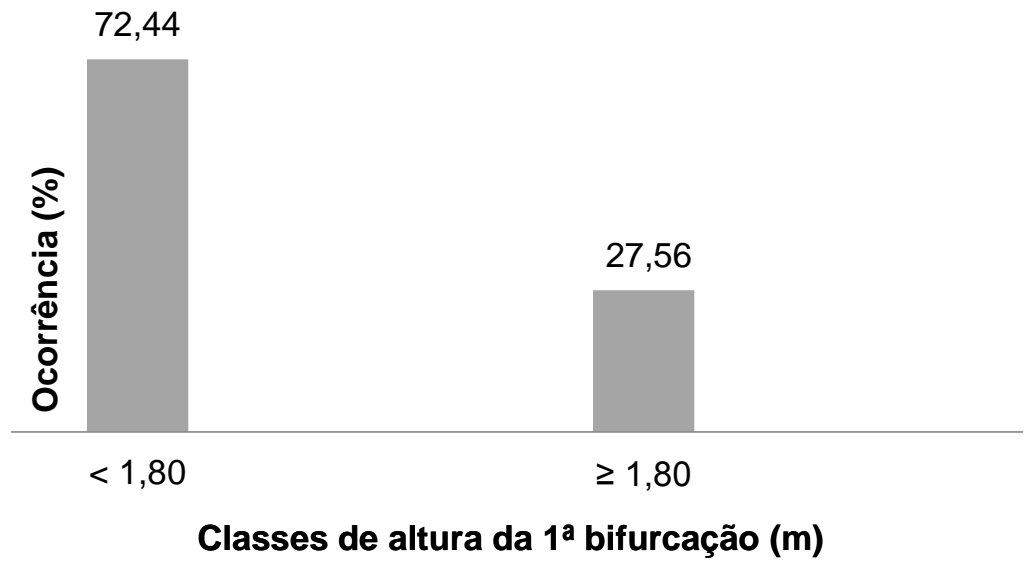

Figura 7. Distribuição da altura da primeira bifurcação $(\mathrm{m})$

Figure 7. Distribution of the height of the first bifurcation height $(\mathrm{m})$

Portanto, esses resultados têm concordância com Melo, Lira Filho e Rodolfo Júnior (2007) que recomendam uma condução das plantas utilizadas na arborização urbana, para que estas não venham a possuir problemas semelhantes no futuro (Figura 8).
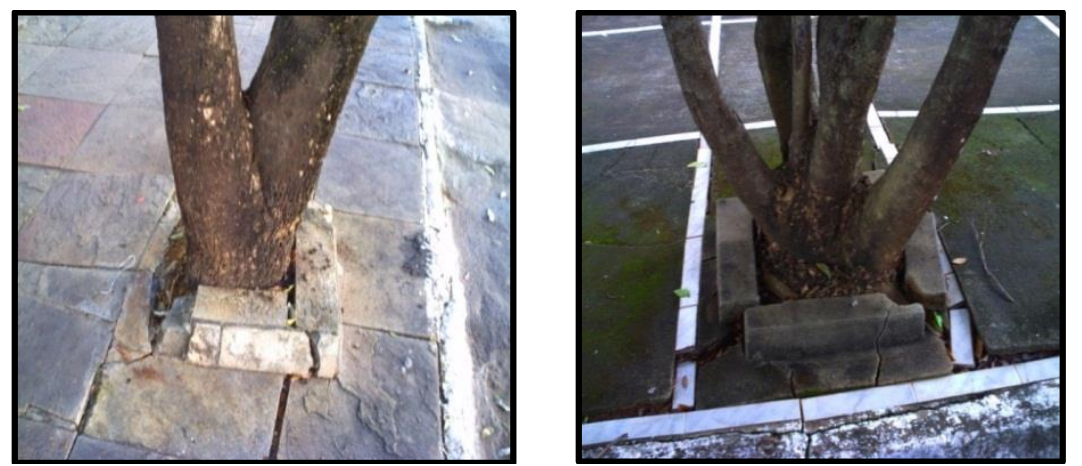

Figura 8. Altura da primeira bifurcação abaixo do recomendado

Figure 8. First bifurcation height below recommended

Com relação aos padrões estabelecidos por Silva, Gonçalves e Paiva (2007), quase $28 \%$ das plantas apresentaram sua primeira bifurcação acima dos 1,80 metros de altura. Porém, foi observado que isso ocorreu, consequentemente, devido algumas árvores já adultas terem recebido podas, com intuito da eliminação de suas ramificações.

\section{Sistema radicular e fitossanidade}

$\mathrm{Na}$ área de estudo, $82 \%$ das calçadas estão pavimentadas. Desta forma, dos 370 indivíduos encontrados, 32,95\% apresentaram o sistema radicular ocasionando depreciação nos passeios, quebrando ou mesmo destruindo as calçadas (Figura 9). 


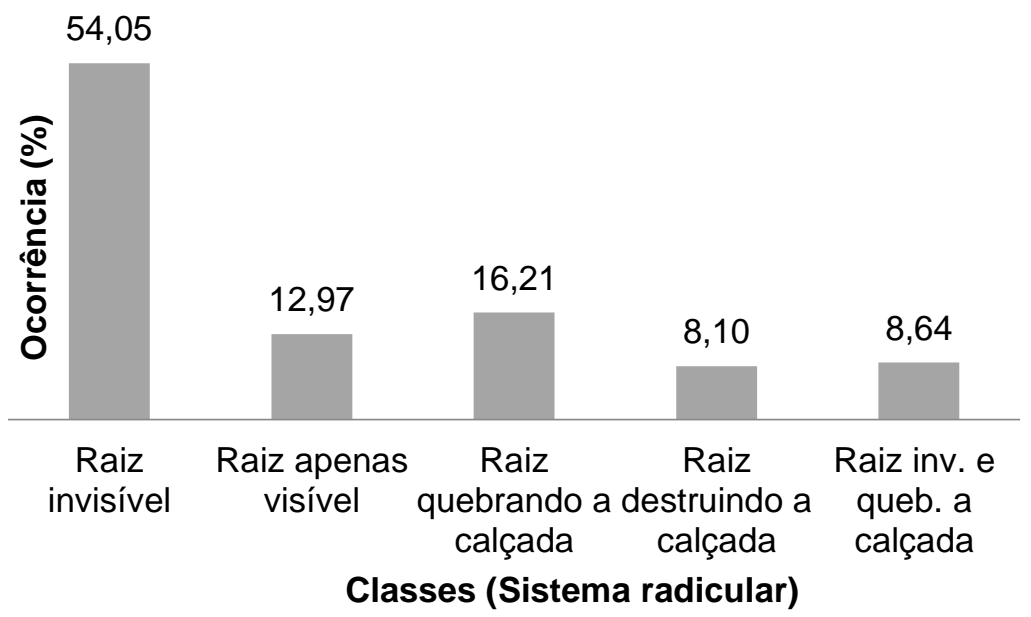

Figura 9. Distribuição das classes do sistema radicular

Figure 9. Distribution of the root system classes

Desses prejuízos, 75,41\% eram de sistema radicular apenas quebrando as calçadas e, um pouco menos que $25 \%$ correspondem a quase total destruição da calçada (Figura 10D). Do total das plantas que possuem as raízes quebrando as calçadas, há cerca de $35 \%$ com raízes invisíveis, mas trincando e quebrando a calçada (Figura 10A e B).
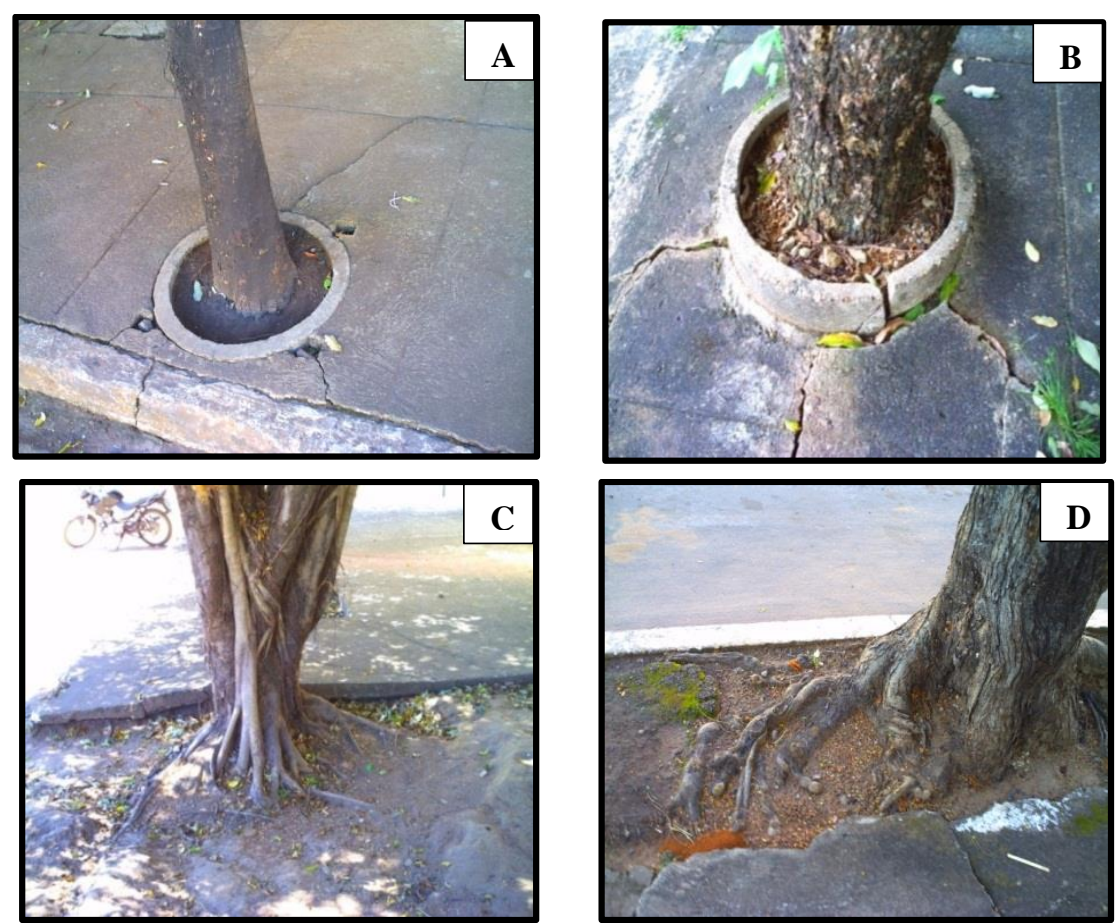

Figura 10. Sistema radicular invisível (A), porém trincando a calçada; sistema radicular invisível, mas rachando a calçada (B); espécie Ficus benjamina com o sistema radicular ficando exposto (C); e sistema radicular da espécie Caesalpinia pluviosa destruindo a calçada (D)

Figure 10. Invisible root system (A), but cracking the sidewalk; Invisible root system, but cracking the sidewalk (B); Species Ficus benjamina with the root system being exposed (C); and root system of Caesalpinia pluviosa destroying the sidewalk (D) 
Duas das explicações para este cenário é que: essas áreas talvez possuam solo raso ou muito compactado e não profundo para o desenvolvimento adequado das raízes; devido à falta de espaço disponível (área permeável) para o pleno desenvolvimento das árvores (OLIVEIRA et al., 2017). Com o solo raso ou compactado, a tendência do sistema radicular das plantas é ter um crescimento superficial após atingir a rocha do solo ou a parte muito dura do solo, consequentemente, rachando a calçada. No caso da falta da área permeável, conforme Oliveira et al. (2017), funciona como barreira física impedindo a infiltração da água no solo e, como resultado, limitando o crescimento das plantas. Além disso, algumas espécies não apresentam como característica natural o sistema radicular pivotante, e sim, raízes fasciculadas, como exemplos, as espécies: Ficus benjamina (Figura 10C) e Caesalpinia pluviosa (Figura 10D) que representam, juntas, 8,37\% das plantas catalogadas.

Segundo Sartori e Balderi (2011), Ficus benjamina possui tendência de gerar problemas futuros, pois apresentam raízes tabulares que crescem para os lados e normalmente ficam expostas. No estudo realizado por Meira et al. (2015) na cidade Corumbataí do Sul-PR evidenciaram que Caesalpinia pluviosa apresenta maior ocorrência de afloramento das raízes pela falta de espaço necessário para seu desenvolvimento e, em razão disso, causando prejuízos nas calçadas.

Analisando as condições fitossanitárias da arborização presente nas calçadas, a mesma foi considerada de forma geral como sadia (Figura 11), pois foi observado na área mais de $90 \%$ dos indivíduos com situações boas e satisfatórias e, apenas 0,27\% dos indivíduos foi encontrado morto durante o levantamento. Situação semelhante com a encontrada por Melo, Lira Filho e Rodolfo Júnior (2007) quando estavam analisando a arborização no bairro Bivar Olinto, Patos-PB, na qual observaram-se que $88,47 \%$ das árvores se encontravam em boas condições fitossanitárias.

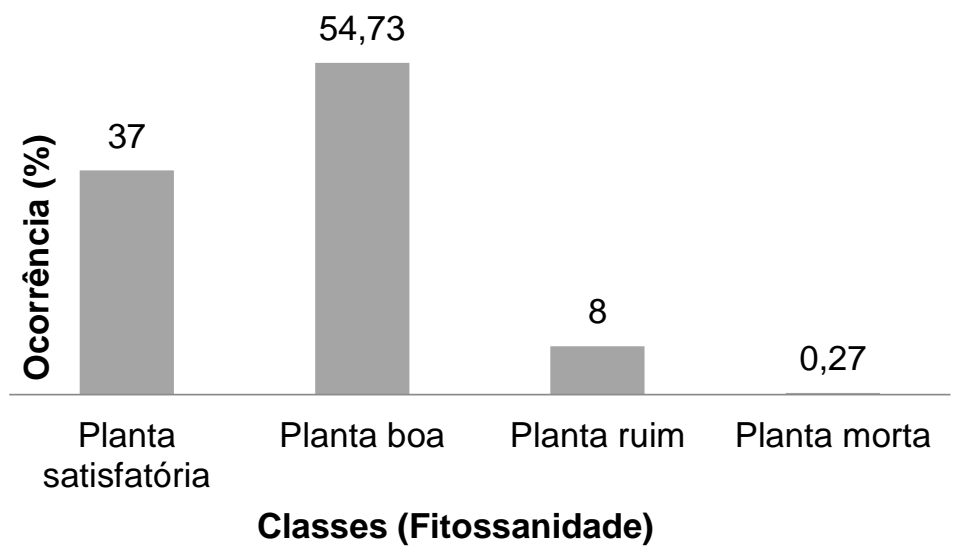

Figura 11. Distribuição das classes de fitossanidade

Figure 11. Distribution of phytosanitary classes 
O restante $(8 \%)$ das plantas apresentavam situações ruins devido às pragas e doenças, como exemplo, foi visto plantas com ocos no interior dos troncos, causado por cupins e, também, ramos desfolhados, evidentemente causados por formigas ou lagartas. Conforme Semam (2013), um dos ataques mais constantes nas árvores é ocasionado por cupins, tanto na base quanto na interseção do tronco e que, a presença de cupins normalmente ocorre nos períodos de poda das árvores, em razão da entrada de patógenos através das áreas expostas ou rachaduras dos troncos.

No trabalho de Duarte et al. (2008), onde analisaram cupins na arborização urbana da zona 1 de Maringá-PR mostrou maior relação dos cupins com as espécies mais fragilizadas (condições gerais ruins), que normalmente são aquelas mais frequentes, mais velhas e com injúrias mecânicas e problemas fitossanitários graves.

Dessa forma, de modo a dar continuidade à qualidade ambiental local, deve dá mais atenção quanto aos problemas fitossanitários, evitando como exemplo, podas inadequadas em seus indivíduos arbóreos, e empregando espécies mais adequadas a cada local, assim, evitaria grande parte destas podas. Além disso, recomenda-se o plantio intercalar de novas mudas, ou, mediante autorização do poder público, em razão do risco de queda e acidentes que alguns indivíduos trazem, ou, por estarem mortos (0,27\%), a eliminação e posteriormente o plantio de outras árvores no mesmo local ou nas proximidades.

\section{CONCLUSÕES}

Os principais problemas verificados na arborização nas calçadas da região central da cidade foram: grande frequência da espécie Licania tomentosa; baixa frequência de indivíduos de grande parte das espécies; presença de espécies de médio a grande porte abaixo das redes aéreas de distribuição; mais da metade dos indivíduos com início da altura da primeira bifurcação abaixo do recomendável; e uma grande quantidade de indivíduos com o sistema radicular causando danos as calçadas, devido os mesmos não ter um canteiro com estrutura física do solo ou um tamanho adequado para o seu desenvolvimento.

Diante disso, conclui-se que é de suma importância o planejamento adequado da arborização na área estudada, pois assim, irá minimizar os conflitos com o sistema estrutural do local, bem como redução de transtorno à população. Dessa forma, sugere-se: a paralisação do plantio da espécie de maior frequência e o aumento de indivíduos de outras espécies adequadas as características da cidade, favorecendo assim, como exemplo, a diversidade da fauna urbana, principalmente as de aves; o plantio de espécie de pequeno porte abaixo das redes aéreas e de médio a grande porte em áreas que não possuam as redes de distribuição; implantação de mudas com altura da primeira bifurcação, no mínimo, acima de 1,80 metros; 
uso de espécies com o sistema radicular pivotante, bem como a análise do solo onde as mesmas serão plantadas, com intuito, principalmente, de averiguar se o solo é raso ou está muito compactado, e também verificar e planejar o tamanho do canteiro, pois assim a árvore terá espaço adequado para se desenvolver.

Enfim, usar espécies com características desejáveis ao meio, pois as mesmas irão permanecer a longo prazo no local. Como exemplos de espécies que podem ser usadas nas calçadas têm-se: Andira fraxinifolia Benth. (angelim-do-mato), Connarus regnellii G. Schellenb. (camboatã-da-serra), Cyclolobium vecchii A. Samp. ex Hoehne (louveira), Dictyoloma vandellianum A. Juss. (tingui), Esenbeckia grandiflora Mart. (pau-de-cutia), Garcinia gardneriana (Planch. e Triana) Zappi (bacupari), Gustavia augusta L. (jandiparana), Ouratea castaneifolia (DC.) Engl. (farinha-seca), Pera glabrata (Schott) Poepp. ex Baill. (laranjeira-docerrado), Trichilia pallens C. DC. (catiguá), Bixa orelana L. (urucum), Vantanea bahiaensis Cuatrec. (mônica) e Ziziphus joazeiro Mart. (joazeiro).

\section{REFERÊNCIAS}

ALMEIDA, D. N.; RONDON NETO, R. M. Análise da arborização urbana de duas cidades da região norte do estado de Mato Grosso. Revista Árvore, Viçosa, v. 34, n. 5, p. 899-906, 2010.

BRUN, F. G. K.; LINK, D.; JOSÉ BRUN, E. O emprego da arborização na manutenção da biodiversidade de fauna em áreas urbanas. Revista da Sociedade Brasileira de Arborização Urbana, Piracicaba, v. 2, n. 1, p. 117-127, 2007.

DUARTE, F. G.; SANTOS, G. A.; ROSADO, F. R.; DELARIVA, R. L.; SAMPAIO, A. C. F. Cupins (Insecta: Isoptera) na arborização urbana da zona 1 de Maringá - PR. Revista em Agronegócios e Meio Ambiente, v.1, n.1, p.87-99, 2008.

EMER, A. A.; SILVA, L. da; CADORIN, D. A.; MELLO, N. A. de. Avaliação quantitativa e qualitativa da arborização do bairro Santa Terezinha na cidade de Pato Branco (PR). Ambiência, Guarapuava, v. 9, n. 1, p. 129-143, 2013.

INSTITUTO BRASILEIRO DE GEOGRAFIA E ESTATÍSTICA (IBGE). População estimada: Gurupi-TO. Disponível em: <https://cidades.ibge.gov.br/xtras/temas.php?codmun=170950 \&idtema=130> Acesso em: 02 dez. 2017.

LORENZI, H. Árvores brasileiras: manual de identificação e cultivo de plantas arbóreas nativas do Brasil. Nova Odessa: Instituto Plantarum, v. 1, 2008. 368p.

MARTINS, L. F. V.; ANDRADE, H. H. B. de; HANISCH, R. F.; DE ANGELIS, B. L. D.; CAXAMBU, M. G. Análise da compatibilidade da arborização viária com o ambiente construído na cidade de Luiziana, Paraná, Brasil. Revista da Sociedade Brasileira de Arborização Urbana, Piracicaba, v. 6, n. 3, p. 103-127, 2011.

MEIRA, G. R. N.; TEXEIRA, G. G. M.; VENTURIN, P. R. F.; GOTTSTEIN, P.; CAXAMBU, M. G. Avaliação quali-quantitativa de espécies arbóreas no perímetro urbano da cidade de 
Corumbataí do Sul - PR. Revista da Sociedade Brasileira de Arborização Urbana, Piracicaba, v. 10, n. 4, p. 36-49, 2015.

MELO, R. R. de; LIRA FILHO, J. A. de; RODOLFO JÚNIOR, F. Diagnóstico qualitativo e quantitativo da arborização urbana no bairro Bivar Olinto, Patos, Paraíba. Revista da Sociedade Brasileira de Arborização Urbana, Piracicaba, v. 2, n. 1, p. 64-80, 2007.

MINHOTO, E. S.; MONTEIRO, E. A.; FISCH, S. T. V. Arborização viária na cidade de Taubaté, SP: no centro comercial histórico e um bairro residencial moderno. Revista da Sociedade Brasileira de Arborização Urbana, Piracicaba, v. 4, n. 2, p. 82-96, 2009.

MIRANDA, Y. C.; MACHADO, M de S.; SILVA, L. dos S.; ESTEVAM, R.; MARTINS NETO, F. F.; CAXAMBU, M. G. Análise quali-quantitativa da arborização de ruas do município de Godoy Moreira - PR. Revista da Sociedade Brasileira de Arborização Urbana, Piracicaba, v. 10, n. 1, p. 71-81, 2015.

OLIVEIRA, L. M. de; SANTOS, A. F. dos; SOUZA, P. A. de; ALVES, K. C. C. de L. F.; GIONGO, M. Diagnóstico da arborização nas calçadas de Gurupi, TO. Revista da Sociedade Brasileira de Arborização Urbana, Piracicaba, v. 12, n. 1, p. 105-121, 2017.

QUISSINDO, I. A. B.; OCONOR, E. F.; LUNA, D. P. Avaliação da vegetação arbórea nas principais ruas da cidade do Huambo-angola. Revista da Sociedade Brasileira de Arborização Urbana, Piracicaba, v. 11, n. 1, p. 43-57, 2016.

RABÊLO, D.; SANTOS, A. F. dos; WANDERLEY, R. J. C.; SOUZA, P. A. de; GIONGO, M. Comparação entre dois procedimentos de amostragem para inventário da arborização do centro urbano de Gurupi-TO. Revista da Sociedade Brasileira de Arborização Urbana, Piracicaba, v. 9, n. 4, p. 170-180, 2014.

RAUPP, M. J.; CUMMING, A. B.; RAUPP, E. C. Street tree diversity in eastern North America and its potential for tree loss to exotic borers. Arboriculture \& Urban Forestry, Champaign, v. 32, n. 6, p. 297-304, 2006.

ROMANI, G. de N.; GIMENES, R.; SILVA, M. T.; PIVETTA, K. F. L.; BATISTA, G. S. Análise quali-quantitativa da arborização na praça XV de novembro em Ribeirão Preto - SP. Revista Arvore, Viçosa, v. 36, n. 3, p. 479-487, 2012.

SARTORI, R. A; BALDERI, A. P. Inventário da arborização urbana do município de Socorro SP e proposta de um índice de danos à infra-estrutura das cidades. Revista da Sociedade Brasileira de Arborização Urbana, Piracicaba, v. 6, n. 4, p. 68-89, 2011.

SECRETARIA DO PLANEJAMENTO E DA MODERNIZAÇÃO DA GESTÃO PÚBLICA (SEPLAN). Atlas do Tocantins: subsídios ao planejamento à gestão territorial. 6. ed. rev. atu. Palmas: Seplan, 2012. 80p.

SECRETARIA MUNICIPAL DO MEIO AMBIENTE (SEMAM). Manual de recomendações técnicas para projetos de arborização urbana e procedimentos de poda. 1‥ ed. Prefeitura de Aracruz: Seman, 2013. 34p.

SILVA, A. G. da; GONÇALVES, W.; LEITE, H. G. Estudo comparativo entre os procedimentos de amostragem casual simples e amostragem sistemática em inventário de arborização urbana. Natureza e desenvolvimento, Viçosa, v. 1, n. 1, p. 67-73, 2005. 
SILVA, A. G. da; GONÇALVES, W.; PAIVA, H. N. de. Avaliando a arborização urbana. Viçosa: Aprenda Fácil, 2007. 346p.

SILVA, L. M.; MOCCELLIN, R.; WEISSHEIMER, D. I.; ZBORALSKI, A. R.; FONSECA, L.; RODIGHIERO, D. A. Inventário e sugestões para arborização em via pública de Pato Branco/PR. Revista da Sociedade Brasileira de Arborização Urbana, Piracicaba, v. 2, n. 1, p. 100-108, 2007.

SILVA, T. G.; LEITE, E. C.; TONELLO, K. C. Inventário da arborização urbana no município de Araçoiaba da Serra, SP. Revista da Sociedade Brasileira de Arborização Urbana, Piracicaba, v. 9, n. 4, p. 151-169, 2014.

SOARES, C. P. B.; PAULA NETO, F. de; SOUZA, A. L. de. Dendrometria e Inventário Florestal. Viçosa: UFV, 2009. $275 \mathrm{p}$.

TEIXEIRA, I. F.; SILVA, R. M. da; TATSCH, G. L. Compatibilidade da arborização de ruas da Avenida Celestino Cavalheiro, São Gabriel-RS. Floresta e Ambiente, Seropédica, v. 18, n. 4 p. 438-450, 2011. 